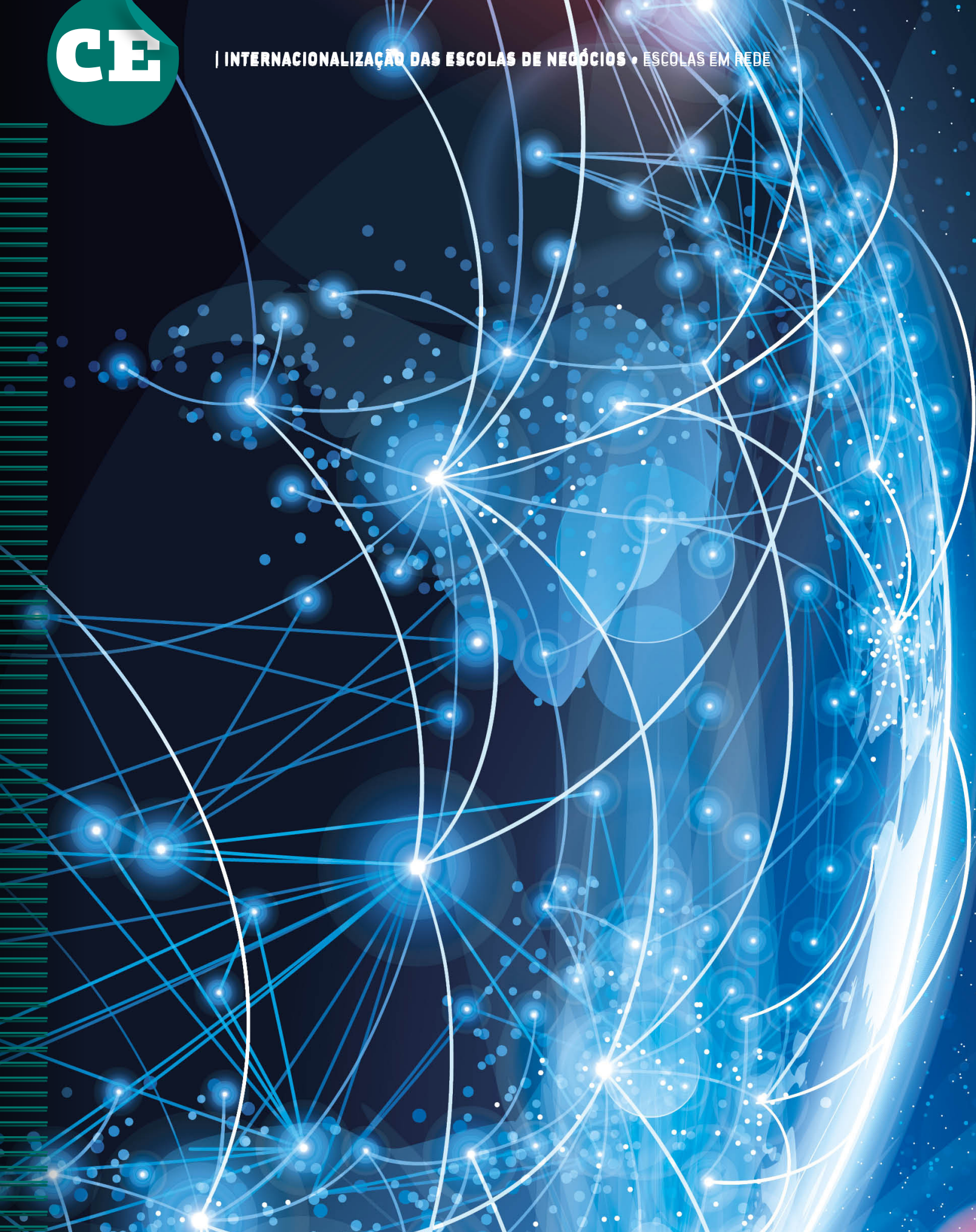




\section{ESCOLAS EM REDE}

| POR JULIA VON MALTZAN PACHECO

\section{Estudantes, ex-alunos, professores e empresas ganham com a união de esforços entre faculdades de administração líderes no mundo.}

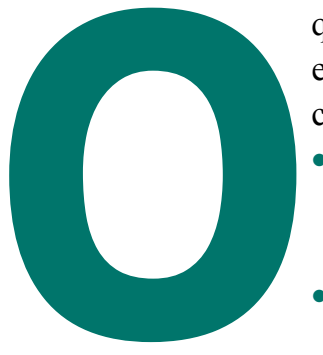

que vem à cabeça quando se associam escolas de administração à internacionalização?

- Intercâmbios de um semestre para experimentar diferentes ambientes acadêmicos e culturais;

- Professores e pesquisas internacionais.

Ambos os aspectos são tipicamente baseados em acordos bilaterais tradicionais com escolas parceiras ao redor do mundo. No entanto, ao entrarmos no século 21, as escolas de administração começaram a implantar estratégias de globalização mais sofisticadas.

Muitas escolas americanas e europeias optaram por abrir novos campi em todos os continentes, especialmente na Ásia (por exemplo, O Instituto de Tecnologia de Massachusetts (MIT), o Instituto Europeu de Administração de Empresas (INSEAD) e a Universidade Luigi Bocconi. Outras iniciaram redes internacionais com o objetivo de fortalecer seu impacto global via atividades de networking. As escolas usam essas alianças para envolver seus stakeholders - ex-alunos, parceiros corporativos e estudantes - em experiências globais com conteúdo local.

As redes permitem que as escolas membros ganhem acesso global a mercados que elas somente alcançariam com significativos aportes financeiros em cada um dos mercados individualmente - e com o risco de a estratégia não dar certo. Diversas escolas, especialmente na China, fecharam seus campi no exterior por causa dos altos custos fixos e/ou do baixo retorno. As redes são uma saída que reduz significativamente os custos e os riscos de investimentos. Os membros aprendem com seus pares sobre as características de um país e/ou de uma região.

Além disso, as escolas de administração regularmente agem como intermediárias para companhias interessadas em explorar oportunidades de negócio. Quando uma empresa entra em um novo mercado, como na África, ter conhecimento local é essencial para evitar fracassos. As 


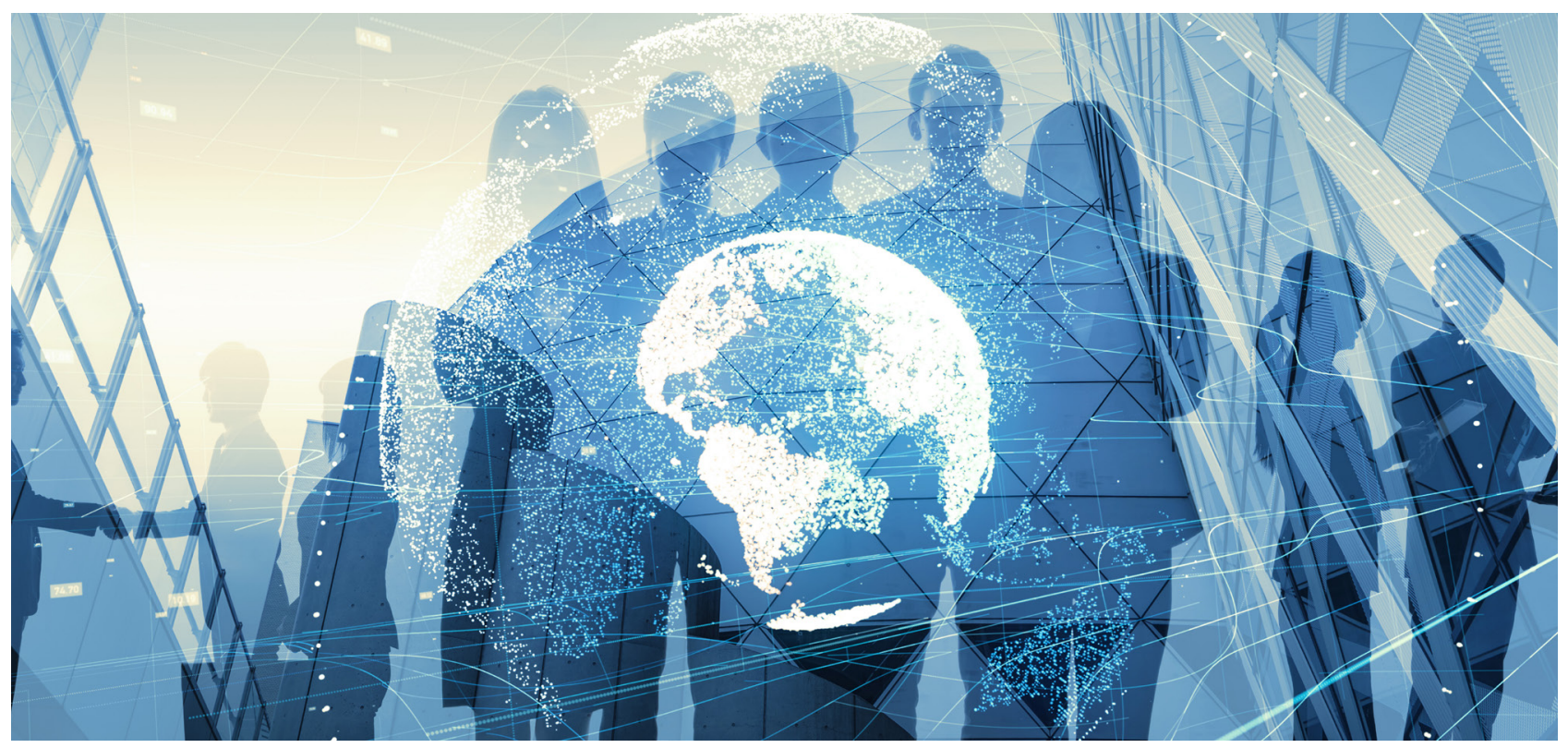

redes internacionais apoiam as escolas individuais no seu papel de intermediárias oferecendo canais para que possam encontrar as melhores formas de guiar as empresas nesse processo.

\section{O EXEMPLO DA GNAM}

Fundada em 2012, a Global Network for Advanced Management (GNAM) é um exemplo de uma rede bem-sucedida. Com 30 escolas de administração membros, a GNAM tem como objetivos "multiplicar conexões, construir capacidades globais e ir além das fronteiras". Uma das ferramentas mais importantes da GNAM são as tecnologias digitais, que permitem às escolas se conectarem internacionalmente e quase instantaneamente, 24 horas por dia, sete dias por semana, com estudantes, ex-alunos, parceiros corporativos e professores.

Se forem administradas sem grande burocracia, as redes podem impulsionar inovações no ensino da administração. A GNAM desenvolveu diversas ferramentas de ensino novas para seus estudantes e para seus ex-alunos, tais como:

- Global Network Weeks: o programa já permitiu que mais de quatro mil estudantes de MBA de 23 escolas membros participassem de um curso de uma semana, com direito a quatro créditos, nas maiores escolas de administração do mundo, como University of California, Yale University, Higher Education Comission (HEC), Bocconi, Hong Kong University of Science and Technology (HKUST), Fudan University e Escola de Administração de Empresas de São Paulo da Fundação Getulio Vargas (FGV EAESP), juntando pares de todo o mundo sem pagar nenhum valor adicional à mensalidade do curso;

- Global Network Courses: são cursos online com direito a quatro créditos sobre tópicos como empreendedorismo, estratégias de marketing global e inovação, exclusivamente oferecidos a estudantes de MBA das escolas membros da GNAM;

- Global Network Surveys: são pesquisas por meio das quais é possível obter valiosos insights da considerável base de estudantes da rede. Na última pesquisa, 4.800 estudantes de MBA e ex-alunos com experiência profissional em 109 países responderam a questões sobre "women in the global workforce". Os resultados apontaram para os principais fatores que prejudicam as carreiras das mulheres no mundo todo e possibilitaram o levantamento de recomendações para solucionar os problemas.

Vale citar também seminários, conferências, competições etc. Por meio desses diferentes eventos, redes como a GNAM proporcionam valor adicional, ao agregar a $e x-$ pertise de escolas de administração de nível mundial. Por exemplo, na unconference anual da GNAM, professores, ex-alunos e estudantes podem identificar novas tendências no campo do empreendedorismo e da inovação, desenvolver temáticas para pesquisa aplicada e criar instrumentos/ ferramentas de ensino.

Além disso, com a comunicação horizontal própria dessas redes, é possível promover a transferência de conhecimento quase imediata das mais recentes tendências nos negócios - tais como as inovações de última geração ou os 
mais recentes desafios no ambiente corporativo. Essa troca beneficia não apenas estudantes e professores, mas também chama a atenção de ex-alunos e empresas para tópicos urgentes e oferece oportunidades de conseguirem alcançar vantagens competitivas sobre concorrentes ou perseguirem novos mercados e clientes.

\section{O EXEMPLO DA CEMS}

As redes permitem que as escolas membros façam benchmark em um ambiente seguro. Em outra rede da qual a FGV EAESP participa, a Global Alliance in Management Education (CEMS), 32 escolas oferecem um curso conjunto de mestrado profissional de um ano em administração internacional que inclui um estágio fora do país de origem e um curso de um semestre em uma das escolas afiliadas.

Para manter os programas de todas as instituições alinhados, equipes de revisão por pares visitam regularmente as escolas e estabelecem alvos de benchmark para o resto da comunidade. Esse procedimento proporciona melhoria constante do ensino e dos serviços e também ajuda a identificar novos desenvolvimentos no setor da educação e a implementá-los rapidamente.

\section{OPORTUNIDADES EXPANDIDAS}

Por meio de alianças internacionais, as escolas de administração podem aumentar as oportunidades de networking para seus ex-alunos. Tais escolas devotam bastante tempo e investimento para alcançar seus ex-alunos, fornecendo redes de relacionamento, plataformas para aprendizado contínuo e recebendo feedback sobre as suas experiências profissionais e suas necessidades. Mediante escolas parceiras, dessa forma, os ex-alunos podem se conectar aos seus pares de outras escolas de administração de nível mundial e acessar um conjunto maior de oportunidades de negócios e de trabalho. Eventos conjuntos de redes de alumni também permitem que as escolas de administração não percam de vista ex-alunos de locais distantes, onde apenas poucos deles estejam localizados. Nos últimos anos, a rede GNAM realizou eventos para ex-alunos em Tóquio, Xangai, Nova York, Vancouver, Berlim, Cidade do Cabo - para mencionar apenas alguns exemplos.

Como stakeholders das escolas de administração, os parceiros corporativos ganham com as redes globais em diversas frentes. No caso do recrutamento de profissionais, sejam jovens, sejam experientes, as empresas têm acesso a uma base ampla e altamente qualificada de estudantes e ex-alunos não só de um país, mas de uma variedade muito maior de países. Além disso, por exemplo, projetos de negócios

\section{As redes permitem que as escolas participantes ganhem acesso global a mercados que somente alcançariam com significativos aportes financeiros - e com o risco de a estratégia não dar certo.}

realizados por estudantes de todo o mundo permitem que as empresas testem estratégias globais em pequena escala e forneçam os primeiros insights para posteriores tomadas de decisão. Simultaneamente, as escolas de administração enriquecem as experiências internacionais dos estudantes nesses projetos internacionais, embora locais.

\section{EM POUCAS PALAVRAS}

As redes globais das escolas de negócios oferecem a seus stakeholders - ex-alunos, estudantes, professores e empresas: - A expertise de escolas de administração de nível mundial;

- Transferência de conhecimento sobre as mais recentes tendências nos negócios;

- Pesquisa aplicada de impacto e inovação no ensino da administração;

- Um conjunto maior e mais eficiente de oportunidades de networking;

- Acesso global a novos mercados com know-how local a baixo custo.

Uma estratégia em que todos ganham.

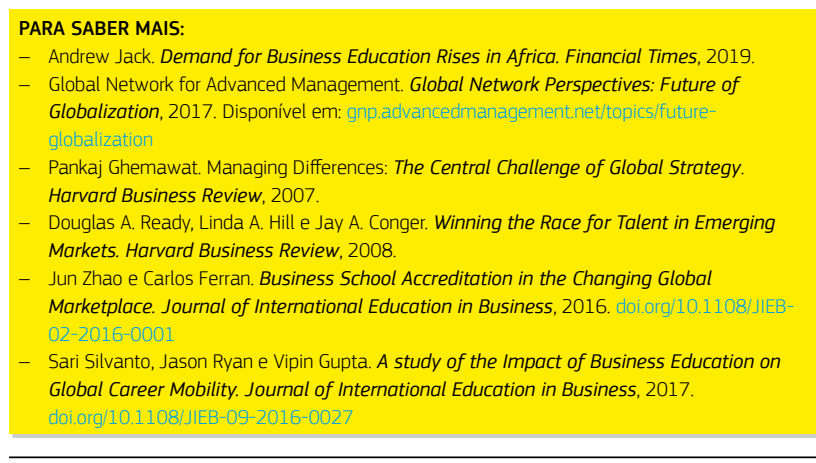

JULIA VON MALTZAN PACHECO > Diretora associada de relações internacionais e professora da FGV EAESP > julia.pacheco@fgv.br 